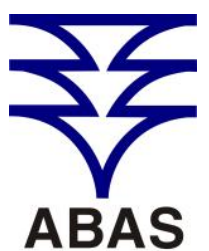

ASSOCIACAOAOBRASILEIRADE
AGUAS SUBTERRANEAS www.abas.org

\section{ANÁLISE DA SALINIDADE DOS AQUÍFEROS NA BACIA DO MACACU, ITABORAÍ, RJ}

\author{
ASSESSMENT OF SALINITY FROM MACACU GROUNDWATER \\ BASIN, ITABORAÍ, RJ, BRAZIL
}

Olga V. de Oliveira Gomes ${ }^{1}$, José Ribeiro Aires², Eduardo Duarte Marques ${ }^{3}$, Emmanoel Vieira Silva-Filho ${ }^{4}$

Artigo recebido em: 23/02/2013 e aceito para publicação em: 19/05/2013

\begin{abstract}
The hydrogeochemistry of aquifers in Itaboraí,RJ was studied between 2009 and 2010, when was verified different salinity values for the Macacu Aquifer System, Aluvial-Lacustrine and Fluvial-Marine. This work presents information about the source of dissolved constituents of the groundwater in the Macacu sedimentary basin by hydrodynamic analysis and the ratio $\mathrm{rCl} / \mathrm{rBr}$. The $\mathrm{rCl} / \mathrm{rBr}$ pointed out four different sources of groundwater. The Group 1 is formed by groundwater from the recharge area, with $\mathrm{rCl} / \mathrm{rBr}=100$ to 539 and $\mathrm{Cl}$ concentrations lower than 25 $\mathrm{mg} / \mathrm{l}$. The Group 2 is located in a discharge area, presents $\mathrm{rCl} / \mathrm{rBr}=1007$ to 1.500 and $\mathrm{Cl}$ concentrations ranging from 141 to $178 \mathrm{mg} / \mathrm{l}$. Those waters come from the Aluvial-Lacustrine aquifer system and part from Macacu aquifer. The Group 3 is formed by groundwater with $\mathrm{rCl} / \mathrm{rBr}=10$ to $591 \mathrm{mg} / \mathrm{l}$ and $\mathrm{Cl}$ concentrations ranging from 443 to $745 \mathrm{mg} / \mathrm{l}$. Those waters belong to the Aluvial-Lacustrine aquifer system with high $\mathrm{Cl}$ concentrations, notable values by $\mathrm{Br}$ concentrations, which are linked to the organic matter. The Group 4 is formed by groundwater with $\mathrm{rCl} / \mathrm{rBr}=$ 274 to 595 and the highest $\mathrm{Cl}$ concentrations (803 to $1.246 \mathrm{mg} / \mathrm{l}$ ). Those waters are part of the Fluvial-Marine aquifer, where occurs marine intrusion. Even with a restricted distribution of sediments Macacu Basin, aquifers showed different concentrations of salts that reflect diverse geochemical behavior in the region.
\end{abstract}

Keywords: Groundwater. Marine intrusion. $\mathrm{Cl} / \mathrm{Br}$ ratio. Brazil.

Resumo: A hidrogeoquímica dos aquíferos no município de Itaboraí foi estudada entre os anos de 2009 e 2010 quando foram verificadas salinidades distintas nas unidades hidroestratigráficas sedimentares do sistema Macacu, do Aluvial-lacustrino e do Fluvial-marinho. Os dados físico-químicos e a razão $\mathrm{rCl} / \mathrm{rBr}$ apontaram quatro origens distintas para as águas subterrâneas da Bacia Sedimentar do Macacu. O Grupo 1 formado por águas de recarga com valores da $\mathrm{rCl} / \mathrm{rBr}=100$ a 539 e $\mathrm{Cl}$ inferiores a $25 \mathrm{mg} / \mathrm{l}$. O Grupo 2, localizado numa área de descarga, apresentou valores de $\mathrm{rCl} / \mathrm{rBr}=1.007$ a 1.500 e $\mathrm{Cl}$ que variou de 141 até $178 \mathrm{mg} / \mathrm{l}$. O Grupo 3 é de águas com $\mathrm{rCl} / \mathrm{rBr}$ entre 10 a 591, mas com concentrações de $\mathrm{Cl}$ que variaram de 443 até $745 \mathrm{mg} / \mathrm{l}$, pertencentes ao aquífero Aluvial-lacustrino que, apesar das altas concentrações de $\mathrm{Cl}$, possuem relevantes valores de $\mathrm{Br}$ provavelmente associados à matéria orgânica. O Grupo 4 é formado por águas subterrâneas com razões $\mathrm{rCl} / \mathrm{rBr}$ entre 274 e 595 e com as maiores concentrações de $\mathrm{Cl}$ (803 até $1.246 \mathrm{mg} / \mathrm{l})$, pertencentes ao aquífero Fluvial-marinho, onde ocorre a intrusão marinha. Apesar da distribuição restrita dos sedimentos da Bacia do Macacu, os seus sistemas aquíferos possuem salinidades distintas que refletem comportamentos geoquímicos diversificados na região.

Palavras-Chave: Água subterrânea. Intrusão marinha. Razão cloreto/brometo. Brasil.

\section{INTRODUÇÃO}

A Bacia Hidrográfica da Baía da Guanabara integra a Região Metropolitana do Estado do Rio de Janeiro (RMRJ) e abrange a bacia sedimentar do Macacu, onde ocorrem sistemas aquíferos como o sistema Macacu, formado por sedimentos terciários com espessuras que podem ultrapassar
190 metros, além de sistemas aquíferos quaternários formados por sedimentos aluviais-lacustrinos e sedimentos fluviais-marinhos que podem alcançar 40 metros de profundidade (Figura 1). A região classificada, até então, como área rural encontra-se em período de transição para uso indus-

\footnotetext{
${ }^{1}$ Departamento de Ciências Administrativas e do Ambiente, Instituto Três Rios, Universidade Federal Rural do Rio de Janeiro (olga_gomes@ufrrj.br).

2 ABAST, PETROBRAS, Rio de Janeiro, RJ (aires@petrobras.com.br).

${ }^{3}$ CPRM - Serviço Geológico do Brasil, Belo Horizonte, MG (eduardo.marques@cprm.gov.br).

${ }^{4}$ Departamento de Geoquímica, Instituto de Química, Universidade Federal Fluminense, Niterói, RJ (geoemma@vm.uff.br).
} 
trial a partir da instalação do Complexo Petroquímico do Estado do Rio de Janeiro (COMPERJ), iniciada em 2008. Com a iminência de urbanização da área, em consequência da instalação do COMPERJ, estudos de diagnósticos ambi- entais na região, dentre eles o da preservação dos recursos hídricos, vêm sendo desenvolvidos. Este artigo é produto do monitoramento dos aquíferos sedimentares realizados entre os anos de 2009 e 2010 na região.
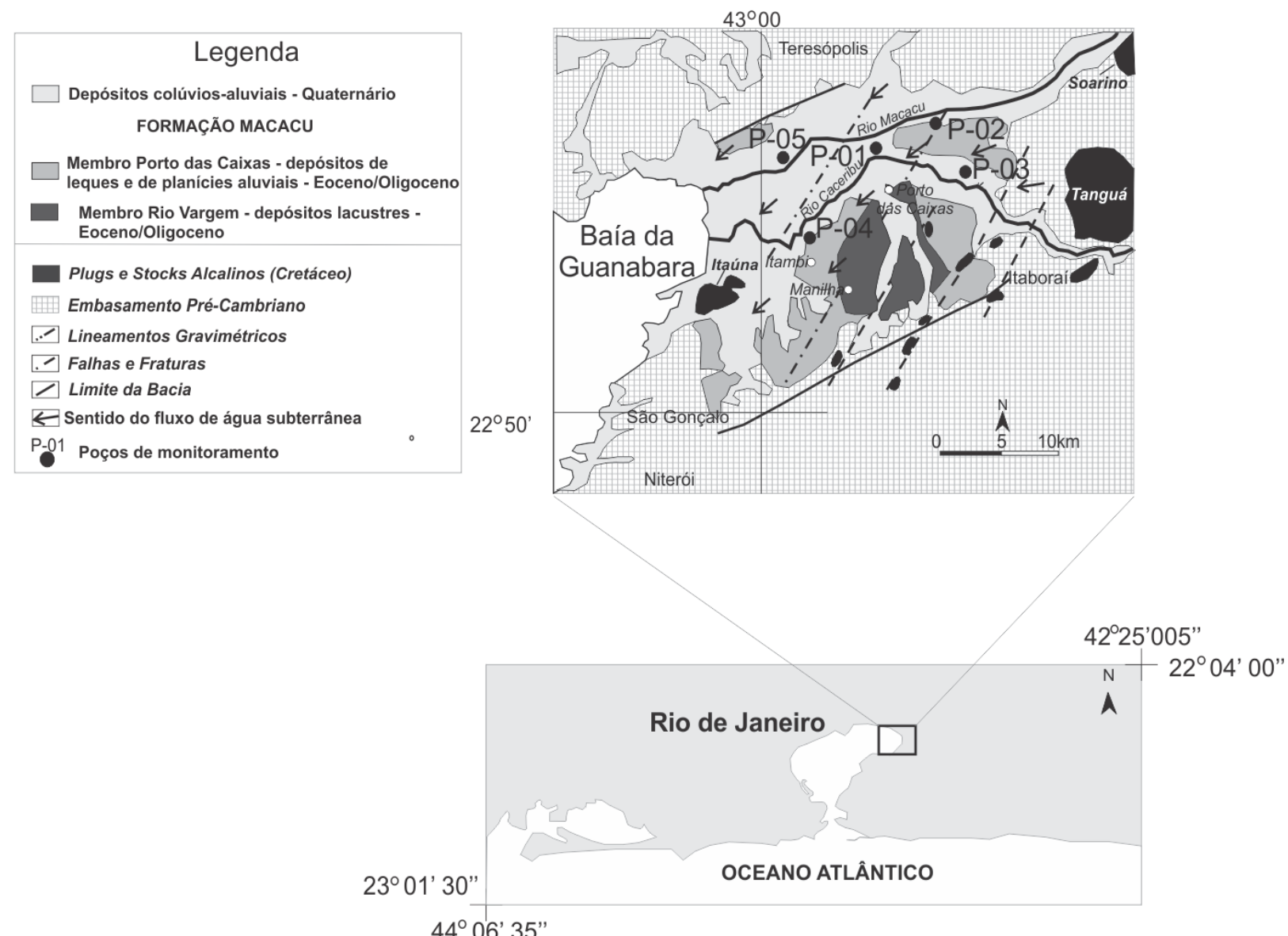

Figura 1 - Localização dos poços de monitoramento da área de estudos. Arcabouço estrutural da Bacia do Macacu (Fonte: MEIS E AMADOR, 1977; PENHA, 1979; D’ALCOLMO, 1982; FERRARI E FERRAZ, 1988) e subunidades litoestratigráficas da Formação Macacu propostas por Ferrari (2001).

Figure 1 - Location of the monitoring wells in the study area. Structural framework Basin Macacu (MEIS \& AMADOR, 1977; PENHA, 1979; D’ALCOLMO, 1982; FERRARI \& FERRAZ, 1988) and lithostratigraphic subunits of Macacu Formation by Ferrari (2001).

O monitoramento da condutividade elétrica $(\mathrm{CE})$ realizado nesses aquíferos revelou grande heterogeneidade nas concentrações de sais dissolvidos sugerindo processos de salinização nas águas subterrâneas da Bacia Sedimentar de Itaboraí.

$\mathrm{O}$ estudo da $\mathrm{rCl} / \mathrm{rBr}$, associada aos teores de cloreto, apresenta-se bem difundido na Espanha, Portugal, Austrália, Canadá e E.U.A. e baseia- se no entendimento de que nem toda salinidade da água subterrânea tem a sua origem associada ao aerossol marinho, podendo ser influenciada inclusive pela litologia, precipitação atmosférica e pelo uso antrópico. As associações das $\mathrm{rCl} / \mathrm{Br}$ podem indicar cenários distintos sobre a origem das águas subterrâneas, considerando que esses íons, uma vez dissolvidos, preservam razoá- veis memórias da composição da matéria solúvel responsável pela salinidade na água subterrânea (ALCALÁ \& CUSTODIO, 2008).

A razão entre íons dissolvidos na água subterrânea pode estar relacionada ao material geológico lixiviado e/ou aos processos e ambientes geoquímicos que afetaram a composição dessas águas. No cálculo das razões iônicas, a unidade para a concentração utilizada é meq/l, por isso, utiliza- se o prefixo $r$ antes da denominação dos íons utilizados nas razões $(\mathrm{rCl} / \mathrm{rBr})$. As razões iônicas mais utilizadas nos estudos sobre composição química das águas subterrâneas são: $\mathrm{rMg} / \mathrm{rCa}, \mathrm{rK} / \mathrm{rNa}, \mathrm{rNa} / \mathrm{rCa}, \mathrm{rCl} / \mathrm{rHCO}_{3}$ e $\mathrm{rCl} / \mathrm{rBr}$. A $\mathrm{rCl} / \mathrm{rBr}$ foi aplicada neste estudo por tratar de íons conservativos que refletem melhor a(s) origem(s) da salinidade nas águas subterrâneas. 
Uma vez dissolvidos na água, devido a seu caráter hidrofílico e pequenos raios iônicos, o íon $\mathrm{Br}^{-}$, e, principalmente o $\mathrm{Cl}^{-}$apresentam um comportamento próximo do traçador ideal. Por ser o $\mathrm{Cl}^{-}$muito solúvel e estável, dificilmente se precipita, além de ser um íon que não se oxida e nem se reduz nas águas naturais. Tais características provocam aumentos gradativos desse íon na direção do fluxo da água subterrânea, ou seja, nas áreas de descarga dos aquíferos. O comportamento geoquímico do $\mathrm{Br}^{-}$assemelha-se ao do $\mathrm{Cl}^{-}$, sendo normalmente as concentrações de $\mathrm{Br}^{-}$inferiores a $0,01 \mathrm{mg} / \mathrm{l}$ para as águas doces naturais, menores que $65 \mathrm{mg} / \mathrm{l}$ para as águas de origem marinha e águas subterrâneas. As concentrações de $\mathrm{Cl}^{-}$, de um modo geral, são inferiores a 100 $\mathrm{mg} / \mathrm{l}$ e nos oceanos apresentam valores que oscilam entre 18.000 a $21.000 \mathrm{mg} / \mathrm{l}$ (DAVIS et al., 1998).

Os processos de diluição, evaporação e mistura numa área, ainda que influenciem as concentrações absolutas, alteram muito pouco o resultado da $\mathrm{rCl} / \mathrm{rBr}$, já que esses sais dissolvidos preservam razoáveis memórias da composição do material que deu origem a salinidade (ALCALA; CUSTODIO, 2008). De acordo com Davis et al. (1998), a abundância entre o Cloro e o Bromo no ambiente apresenta uma diferença primordial, tanto na água quanto nas rochas. O Cloro geralmente é de 40 a 8.000 vezes mais abundante que o Bromo. Uma pequena mudança na quantidade de $\mathrm{Br}^{-}$dissolvido na água provoca substancial diferença na $\mathrm{rCl} / \mathrm{rBr}$.

Davis et al. (1998) estudou a $\mathrm{rCl} / \mathrm{rBr}$ em aquíferos rasos de Alberta, Kansas e Arizona (E.U.A.) que variaram entre 100 e 200. Em se tratando de águas subterrâneas influenciadas por esgoto doméstico a variação ficou entre 300 e 600; para aquíferos em áreas urbanas influenciadas por escoamentos superficiais das ruas, a razão variou entre 10 e 100 e para águas associadas a formações que continham Halita, a razão oscilou entre 1.000 e 10.000 . Ainda, no referido estudo, foi determinada a $\mathrm{rCl} / \mathrm{rBr}$ para a água da chuva que oscilou entre 50 e 150. Davis et al. (1998, 2001) também demonstraram que os aquíferos próximos a regiões costeiras dos E.U.A. apresentam $\mathrm{rCl} / \mathrm{rBr}$ aproximadamente de 400 e águas subterrâneas do interior apresentam $\mathrm{rCl} / \mathrm{rBr}<150$.

No sudeste da Austrália, medidas sistemáticas da $\mathrm{rCl} / \mathrm{rBr}$ na água da chuva revelaram razões em torno de 180 a 220 e para aquíferos salinos, a $\mathrm{rCl} / \mathrm{rBr}$ ficou em torno de 400 a 1.300 (CARTWRIGHT et al., 2006; DREVER, 1997). Para Davis et al. $(1998,2001)$, a $\mathrm{rCl} / \mathrm{rBr}$ para águas marinhas está em torno de 650. Alcalá e
Custodio (2008) ainda destacaram que os aquíferos de Portugal e da Espanha estão diretamente influenciados pelo oceano e possuem $\mathrm{rCl} / \mathrm{rBr}$ também em torno de 655. Nesse mesmo estudo, as áreas agrícolas afetadas pelo uso de pesticidas apresentaram diminuição da razão para cerca de 300. Nos aquíferos que percolaram em sedimentos enriquecidos por Halita, os valores da $\mathrm{rCl} / \mathrm{rBr}$ variaram entre 5.000 a 6.000 e aquíferos interioranos de Portugal e da Espanha apresentaram razões de 200 a 500.

Mesmo em se tratando de íons conservativos, a sorção do $\mathrm{Br}^{-}$foi relatada em alguns estudos (TENNYSON; STTERGREN, 1980; LEAP, 1982; BOWMAN, 1984; DAVIS et al., 1985; BOWMAN; RICE, 1985), entretanto, geralmente apenas $10 \%$ do $\mathrm{Br}^{-}$dissolvido é adsorvido por argilas, solo e matéria orgânica, sendo que em soluções ácidas ( $\mathrm{pH} \sim 4,7$ ), a sorção pode alcançar 15 a 20\% (BOGGS; ADAMS, 1992). Davis et al. (1998) também fizeram referência a estudos de águas subterrâneas rasas em Israel que apresentaram maiores concentrações de $\mathrm{Br}^{-}$em função das maiores concentrações de matéria orgânica. Águas subterrâneas rasas podem apresentar, inclusive, $\mathrm{rCl} / \mathrm{rBr}$ menores que a água da chuva em função da acumulação de matéria orgânica, responsável pelo aumento das concentrações de brometo dissolvido.

Considerando-se a larga faixa de concentração de sais dissolvidos verificada nos sistemas aquíferos estudados, o objetivo deste trabalho é a partir da análise hidroquímica das concentrações de cloreto e brometo, classificar as águas subterrâneas provenientes dos sedimentos depositados no leste da Baía da Guanabara, Bacia Sedimentar do Macacu, município de Itaboraí, RJ.

\section{ÁREA DE ESTUDOS}

A área de estudo localiza-se no município de Itaboraí, a leste da Baía da Guanabara entre os rios Guapi-Macacu e Caceribu (Figura 1). De acordo com a SEMADS (1999), o clima na região é subtropical a tropical quente úmido e a média anual da temperatura é de $21^{\circ} \mathrm{C}$. As maiores temperaturas ocorrem entre janeiro e março e, ocasionalmente, em dezembro, sendo o mês de fevereiro, o mês mais quente com temperaturas da ordem de $25{ }^{\circ} \mathrm{C}$ e julho, o mês mais frio, com temperatura média de $20{ }^{\circ} \mathrm{C}$. Dados históricos apontam precipitação média anual em torno de $1.800 \mathrm{~mm}$, com o período chuvoso entre os meses de novembro, dezembro e janeiro (Figura 2). O período de estiagem é constituído pelos meses de junho, julho e agosto podendo sofrer antecipações para maio e se prolongar até setembro (DRM, 1981). 
Segundo SEMADS (1999), a evaporação média anual, na maior parte da região, é de $900 \mathrm{~mm}$.

A área de estudos faz parte do domínio geológico do Graben da Guanabara que está inserido no cinturão móvel da Faixa da Ribeira constituindo uma entidade geotectônica do Neoproterozóico (CPRM, 2001). De acordo com Almeida et al. (1977, 1981), a faixa da Ribeira integra o arcabouço geotectônico da região sudeste do Brasil, circundando o Cráton do São Francisco (CSF), juntamente com outros orógenos, como a Faixa Brasília (oeste) e Faixas Araçuaí (leste) que foram instaladas durante a Orogênese Brasiliana/PanAfricana. A implantação do Graben da Guanabara data do Paleoceno e a Bacia Sedimentar do Macacu formou- se no Eoceno Médio durante contínua evolução do graben e forte regime extensional NW-SE (FERRARI, 2001).

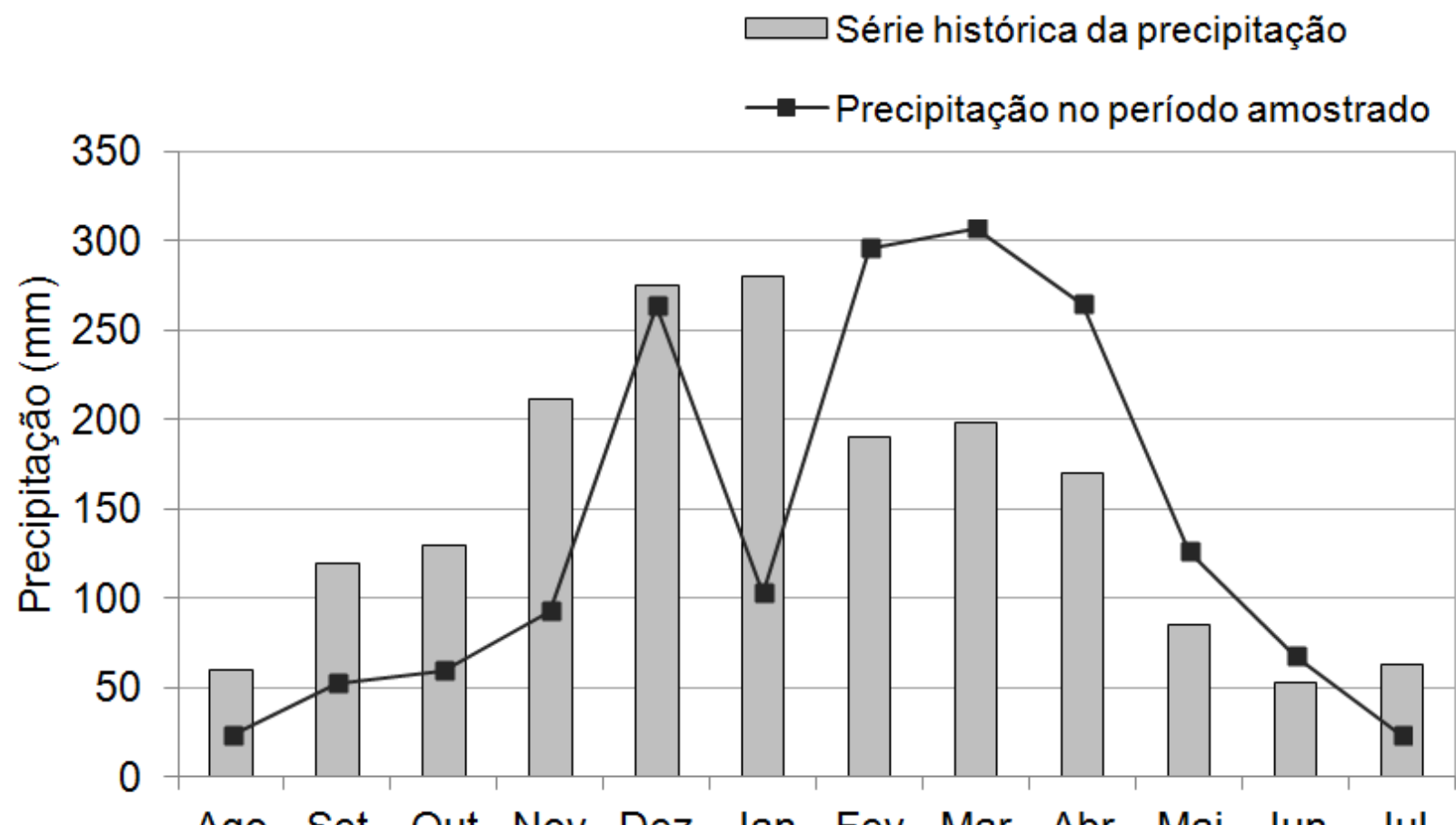

Figura 2 - Série histórica da precipitação em Cachoeira de Macacu $(1976$ - 2007) e dados de precipitação no período de amostragem (2009 - 2010). Fonte: SERLA (2007) e SIMERJ (2010).

Figure 2 - Time series of rainfall in Cachoeira de Macacu (1976 - 2007) and rainfall data in the sampling period (2009 - 2010) by SERLA (2007) and SIMERJ (2010).

No Eoceno foram retrabalhados os depósitos Paleocenos para a Bacia Sedimentar do Macacu, contribuindo inclusive para a formação do conglomerado Itambi que marca a transição do Terciário para o Quaternário, acompanhado da erosão intensa ocorrida na borda norte da Bacia do Macacu, caracterizada pelo desnível acentuado entre a Serra do Mar e a bacia sedimentar do Macacu (ECOLOGUS-AGRAR, 2005).

Os depósitos sedimentares identificados na área de estudos integram o Rift Continental do Sudeste do Brasil (RCSB), uma feição tectônica de idade cenozóica, constituída de uma faixa deprimida e alongada na direção ENE, com cerca de 900 km de extensão (SANT'ANNA; RICCOMINI, 2001).

O embasamento do RCSB é constituído por gnaisses, migmatitos e rochas metamórficas de baixo a médio grau, de idade arqueana a neoproterozóica, associados ao Cinturão de Dobra- mentos Ribeira (HASUI et al. 1975 in SANT'ANNA; RICCOMINI, 2001). O preenchimento sedimentar sintectônico da RCSB, representado por sedimentos aluviais de rios entrelaçados iniciaram a Formação Macacu, sendo que o topo dessa unidade é formado por depósitos colúvio-aluvionares e marinhos. Os referidos sedimentos são de idade terciária e foram identificados em espessuras superiores a $190 \mathrm{~m}$. Os depósitos quaternários que ocorrem na área são: sedimentos litorâneos, sedimentos fluviais, sedimentos paludiais e sedimentos marinhos com espessura máxima de $40 \mathrm{~m}$.

Os eventos hidrotermais formados durante o magmatismo alcalino neocretáceo a Eoterciário são encontrados em algumas regiões do estado do Rio de Janeiro, inclusive no município de Tanguá, vizinho a Itaboraí (SANT'ANNA; RICCOMINI, 2001). Nessa região, Coelho (1987) apontou, como de origem meteórica, as soluções hidrotermais 
encaixadas em estruturas de direção NE-ENE (plugs e stocks) nos gnaisses pré-cambrianos onde estão encaixados o Complexo Alcalino de Tanguá (stock). Essas soluções hidrotermais foram responsáveis pelas mineralizações filoneanas de fluorita encaixadas em estruturas de direção NEENE nos gnaisses pré-cambrianos e nos sienitos cretáceos do Complexo Alcalino de Tanguá, identificado a cerca de $7 \mathrm{~km}$ da área de estudos (Figura 1) datados de 68 M.a. (SONOKI; GARDA, 1988 apud SANT'ANNA; RICCOMINI, 2001).

\section{Unidades hidroestratigráficas}

A área de estudos é formada por quatro unidades hidroestratigráficas: Aquífero Macacu, Aquífero Aluvial-lacustrino, Aquífero Flúviomarinho de característica argilo-arenosa e o embasamento rochoso cristalino.

De acordo com Schlumberger (2007), o Aquífero Aluvial-lacustrino do quaternário é livre e formado por areias e argilas; com matéria orgânica, intensa variação composicional, espessura em torno de $20 \mathrm{~m}$ e vazões em poços instalados nesta unidade estão entre 10 e $20 \mathrm{~m}^{3} / \mathrm{h}$.

O sistema Aquífero Macacu é representado pelas fácies arenosas e conglomeráticas da Formação Macacu intercaladas às fácies de sedimentos mais finos oriundos de fase lacustre, constituindo-se por vezes num aquífero semiconfinado com multicamadas. Ferrari (2001) relacionou as fácies pertencentes à Formação Macacu à uma associação de fácies distinta, denominada Conglomerado Itambi, sobreposta à Formação Macacu. O mesmo autor caracteriza uma associação lacustre pertencente à Formação Macacu denominada Membro Rio Vargem (Figura 1), além das outras associações terrígenas de sedimentos oriundos de leques aluviais e de canais fluviais entrelaçados com inundações episódicas integrantes do Membro Porto das Caixas. As vazões dos poços instalados nesses sedimentos variam de 5 a $42 \mathrm{~m}^{3} / \mathrm{h}$, com capacidade específica média de 0,9 $\mathrm{m}^{3} / \mathrm{h} / \mathrm{m}$.

O sistema Aquífero Fluvial-Marinho é representado pelos terrenos alagados dos manguezais da APA de Guapimirim, consistindo em sedimentos argilosos, ricos em matéria orgânica, típicos de manguezais e de lagunas localizados na região costeira e nos trechos finais dos canais fluviais. Estudos anteriores sugerem vazões médias esperadas para poços instalados nesta unidade entre 5 e $10 \mathrm{~m}^{3} / \mathrm{h}$ (ECOLOGUS-AGRAR, 2005).

O mecanismo principal de fluxo de água subterrânea nas unidades hidroestratigráficas con- sideradas é por meio poroso detrítico. Em conformidade com o fluxo de água superficial, o fluxo regional da água subterrânea na área de estudo dá- se de leste para oeste, em direção à Baía de Guanabara. Localmente, os aluviões contribuem para manutenção do nível de base dos rios, hidraulicamente conectados a estes sedimentos (SCHLUMBERGER, 2007).

\section{MATERIAIS E MÉTODOS}

Foram realizadas seis (6) campanhas mensais de amostragens na área de estudos entre os meses de agosto/2009 até janeiro/2010. Foram monitorados 5 poços, sendo a maioria do tipo multinível (P-01, P-02, P-03 e P-04, Figura 1) com filtros instalados em duas ou três profundidades distintas, ou seja, em camadas aquíferas diferenciadas conforme log da Figura 3. A Tabela 1 apresenta um resumo das características dos poços implantados na região de Itaboraí, com captações em mais de uma profundidade que variaram de 17 a $148 \mathrm{~m}$. Apenas o P-05 instalado na área de manguezal possui só uma captação em torno de $15 \mathrm{~m}$. As unidades hidroestratigráficas amostradas foram: os depósitos aluviaislacustrinos do quaternário, sedimentos quaternários fluvial-marinhos e sedimentos terciários da Formação Macacu.

Quanto à amostragem, antes de iniciar a coleta das amostras, foram realizadas medições dos níveis d'água e calculados os volumes de água contidos em cada poço, necessários para realização da purga. Posteriormente, as amostras foram coletadas com auxílio de mangueiras de polietileno de $1 / 2$ " acopladas a uma bomba submersível modelo WSP-12V-4 - WaTerra. Todos os equipamentos não descartáveis de coleta e medição foram devidamente descontaminados utilizando-se detergente não fosfatado. A mangueira acoplada a bomba e utilizada para a coleta da água subterrânea é de polietileno de alta densidade e, após as coletas, as amostras foram filtradas com membranas de acetato de celulose de $0,45 \mu \mathrm{m}$ de espessura e $47 \mathrm{~mm}$ de diâmetro. Em seguida, as amostras foram preservadas em caixas térmicas com gelo a temperatura de $4{ }^{\circ} \mathrm{C}$ e encaminhadas para o laboratório. As análises dos íons maiores $\left(\mathrm{Na}^{+}, \mathrm{K}^{+}, \mathrm{Ca}^{+2}, \mathrm{Mg}^{+2} \mathrm{Cl}^{-}, \mathrm{SO}_{4}^{-2}\right)$ e do $\mathrm{Br}$ foram realizadas sem diluição prévia através de cromatografia iônica da marca Metrhom. As concentrações de $\mathrm{HCO}_{3}{ }^{-}$foram obtidas por titulação através de medidas de alcalinidade. As medidas de CE (condutividade elétrica) e TDS (Sólidos Totais Dissolvidos) foram realizadas no campo com sonda multiparamétrica. 
Tabela 1 - Características dos poços multiníveis amostrados. Fonte: Schlumberger (2008) adaptado.

Table 1 - Characteristics of the multilevels sampling wells. Source: Schlumberger (2008) adapted.

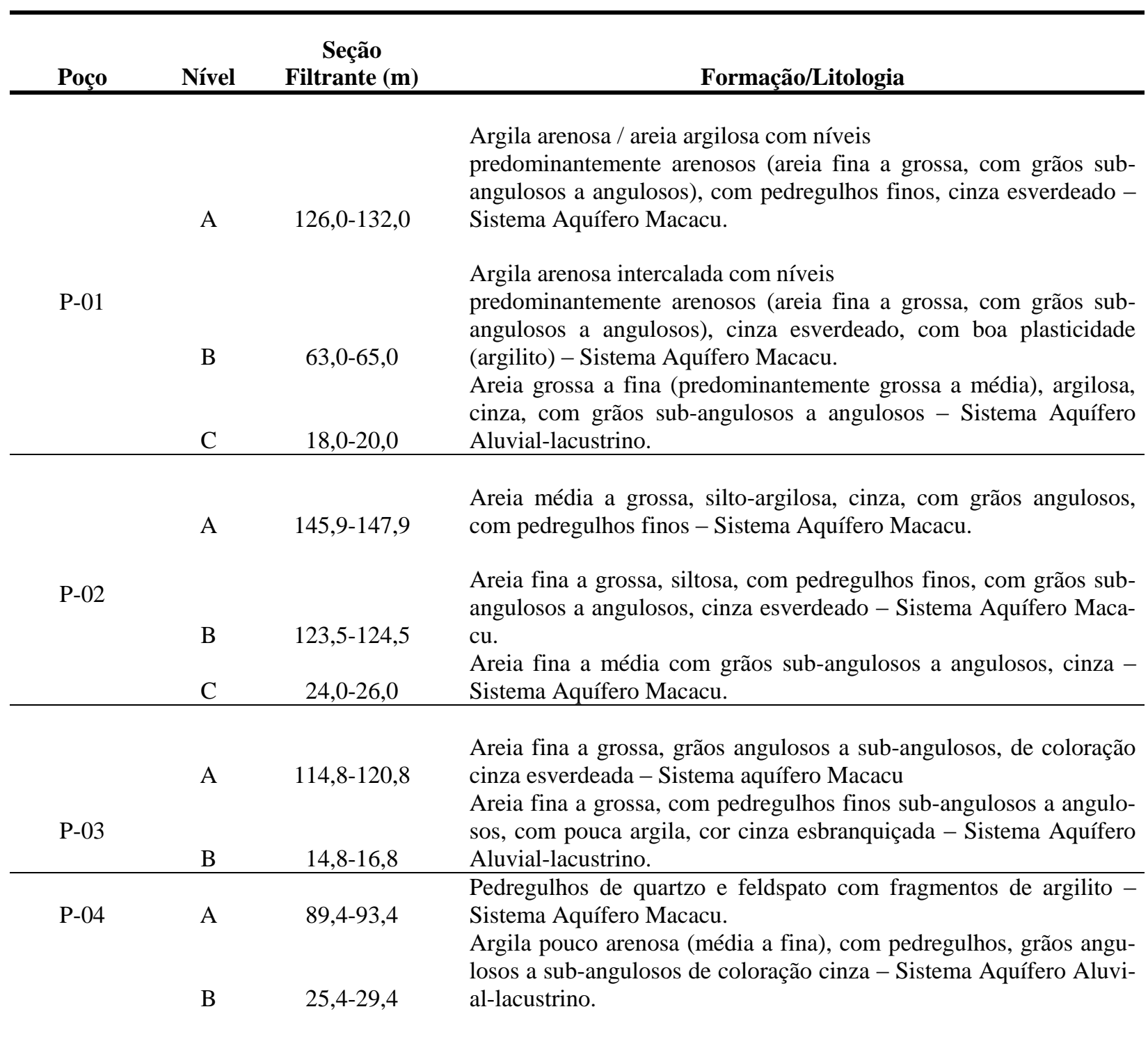
Sistema Aquífero Flúvio-marinho. 


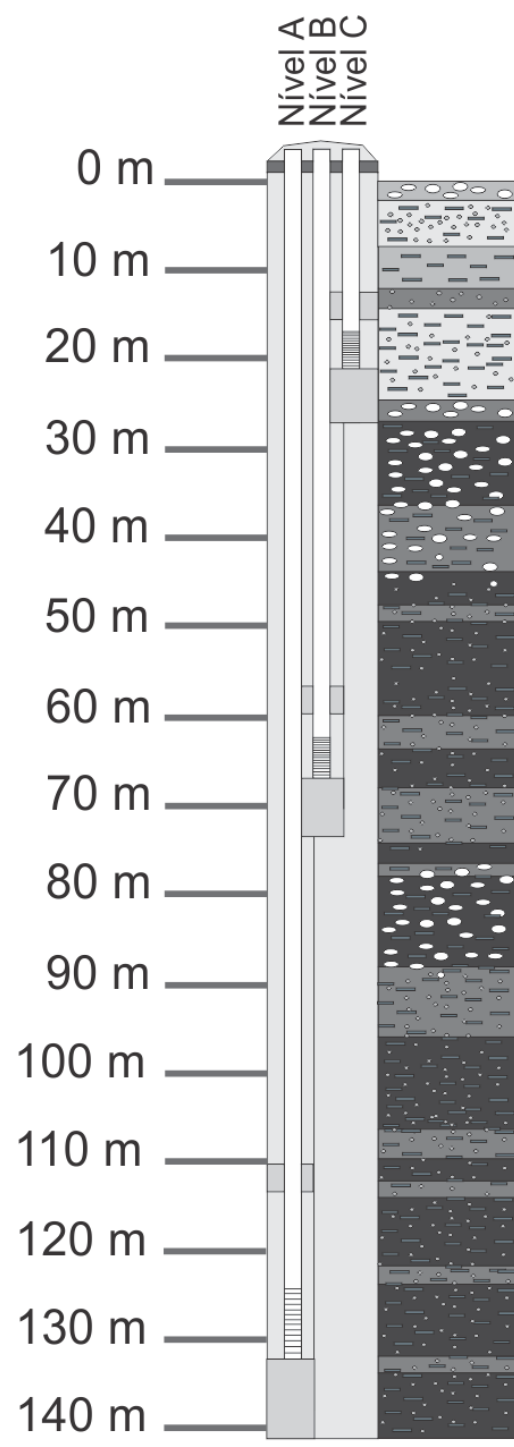

\section{Legenda}

\section{$==$ Areia siltosa marrom avermelhada}

\section{Argila arenosa cinza}

Argila arenosa com lentes de areia e esverdeada

Argila arenosa cinza esverdeada

\section{Filtro de entrada d'água}

Figura 3 - Log do poço P-01 demonstrando captação de água subterrânea em vários níveis. Fonte: Schlumberger (2008).

Figure 3 - Log of well P-01 showing groundwater extraction at various levels (SCHLUMBERGER, 2008).

Buscando identificar a influência marinha no referido local, foram realizadas medidas diárias da variação do nível d'água e da condutividade elétrica através de transdutores de pressão (divers) entre outubro/2009 e janeiro/2010 para os pontos de monitoramento $\mathrm{P}-01 \mathrm{C}$ e no $\mathrm{P}-05$ poços rasos e mais próximos à linha da costa.

\section{RESULTADOS E DISCUSSÃO}

Os resultados das análises da água subterrânea encontram-se na Tabela 2. Na Bacia Sedimentar do Macacu, o menor e maior valor de CE verificado para os sistemas aquíferos durante época de estiagem foi de $71 \mu \mathrm{S} / \mathrm{cm}$ (Sistema Macacu) e $5.651 \mu \mathrm{S} / \mathrm{cm}$ (Sistema Fluvial-marinho), respectivamente. A Figura 4 apresenta a distribuição tridimensional dos valores de $\mathrm{CE}$ dos aquíferos estudados em função da profundidade de captação e das distâncias dos poços em relação à costa. Os maiores valores de $\mathrm{CE}$ foram identificados no $\mathrm{P}$ 05 (Sistema Fluvial-marinho), poço mais raso e mais próximo à linha da costa, além de ser o único poço instalado dentro de uma região de manguezal (APA de Guapimirim). Os menores valores de CE foram identificados nos poços do Sistema Aquífero Macacu profundo (a exemplo do poço P-02B), localizados na borda da bacia sedimentar. Independente do período amostrado e do tipo de aquífero foi observado que os poços distantes até $14 \mathrm{~km}$ da costa (P-01, P-04 e P-05) apresentaram $\mathrm{CE}$ superiores que os demais poços analisados. 
Tabela 2 - Dados hidrogeoquímicos dos sistemas aquíferos da Bacia Sedimentar do Macacu.

Table 2 - Hydrogeochemical datas from aquifer systems of Macacu Sedimentary Basin.

\begin{tabular}{|c|c|c|c|c|c|c|c|c|c|c|c|c|}
\hline & Sistema & $\mathrm{Cl}^{-}$ & $\mathrm{SO}_{4}^{-2}$ & $\mathrm{HCO}_{3}^{-}$ & $\mathrm{Br}^{-}$ & $\mathrm{Na}^{+}$ & $\mathbf{K}^{+}$ & $\mathrm{Mg}^{+2}$ & $\mathrm{Ca}^{+2}$ & \multirow{2}{*}{$\begin{array}{c}\mathbf{C E} \\
(\mu \mathrm{S} / \mathrm{cm})\end{array}$} & \multirow{2}{*}{$\begin{array}{c}\text { TDS } \\
(\mathrm{mg} / \mathrm{L})\end{array}$} & \multirow{2}{*}{$\begin{array}{c}\mathbf{r C l} / \mathrm{Br} \\
(\mathrm{meq} / \mathrm{L})\end{array}$} \\
\hline ID & Aquifero & \multicolumn{8}{|c|}{$(\mathrm{mg} / \mathrm{L})$} & & & \\
\hline P-01A (08/09) & Macacu profundo & 3,7 & 0,78 & 229 & 0,02 & 76,4 & 2,4 & 0,9 & 6,4 & 366 & 182 & 379,35 \\
\hline P-01B (08/09) & Macacu médio & - & 20 & 157 & 0,02 & 48,4 & 4,2 & 1,2 & 5,6 & 183 & 91 & - \\
\hline P-01C (08/09) & Aluvial-Lac. & 626 & - & 176 & - & 143,7 & 18,8 & 19,0 & 181,1 & 2550 & 1268 & - \\
\hline P-02A (08/09) & Macacu profundo & 5,7 & 4,0 & 182 & 0,04 & 9,1 & 5,9 & 3,7 & 38,1 & 376 & 187 & 349,52 \\
\hline P-02B (08/09) & Macacu profundo & 6,8 & 0,03 & 30 & 0,05 & 4,2 & 2,2 & 1,3 & 5,2 & 90 & 45 & 329,57 \\
\hline P-02C (08/09) & Macacu raso & 3,8 & 0,01 & 80 & 0,06 & 18,4 & 5,2 & 2,1 & 7,3 & 197 & 98 & 137,30 \\
\hline P-03A (08/09) & Macacu profundo & - & - & 328 & 0,04 & 3,2 & 1,6 & 0,8 & 4,9 & 375 & 186 & - \\
\hline P-03B (08/09) & Aluvial-Lac. & 7,8 & 5,20 & 240 & 0,05 & 90,2 & 1,1 & 0,9 & 4,1 & 373 & 185 & 387,98 \\
\hline P-04A (08/09) & Macacu médio & 122 & 22,53 & 50 & - & 33,6 & 8,0 & 6,6 & 16,1 & 1104 & 549 & - \\
\hline P-04B (08/09) & Aluvial-Lac. & 158 & 14,55 & 68 & 0,33 & 97,1 & 6,4 & 7,8 & 19,4 & 900 & 448 & 1070,76 \\
\hline P-05 (08/09) & Fluv-mar & - & - & - & 6,02 & 2,3 & 1,2 & 1,3 & 3,9 & - & - & - \\
\hline P0-1A (09/09) & Macacu profundo & - & - & 171 & 0,02 & 107,8 & 6,5 & 0,5 & 12,4 & 364 & 181 & - \\
\hline P-01B (09/09) & Macacu médio & 17 & 29,70 & 50 & - & 26,3 & 4,9 & 0,7 & 6,2 & 181 & 90 & 244,22 \\
\hline P-01C (09/09) & Aluvial-Lac. & 745 & 15,05 & 47,4 & 2,53 & 218 & 18,8 & 19,3 & 182,3 & 2302 & 1145 & 10,23 \\
\hline P-02A $(09 / 09)$ & Macacu profundo & 10,4 & 6,77 & 150 & 0,07 & 11,8 & 7,2 & 2,8 & 39,3 & 343 & 171 & 344,73 \\
\hline P-02B (09/09) & Macacu profundo & - & 9,44 & 35,1 & 0,06 & 17,1 & 3,5 & 0,9 & 7,3 & 97 & 48 & - \\
\hline P-02C (09/09) & Macacu raso & 10,0 & 7,96 & 25 & - & 5,7 & 3,4 & 0,7 & 3,8 & 138 & 67 & - \\
\hline P-03A (09/09) & Macacu profundo & 9,8 & 5,64 & 183 & 0,04 & 76,5 & 1,9 & 0,5 & 5,4 & 375 & 184 & 244,92 \\
\hline P-03B (09/09) & Aluvial-Lac. & 9,8 & 0,04 & 127 & 0,04 & 39,4 & 2,5 & 0,6 & 5,3 & 370 & 179 & 538,65 \\
\hline P-04A (09/09) & Macacu médio & 141 & 28,44 & 330 & 0,22 & 164 & 10,5 & 4,1 & 29,3 & 1120 & 552 & 1420,40 \\
\hline P-04B (09/09) & Aluvial-Lac. & 178 & 19,77 & 50 & 0,40 & 43,3 & 16,6 & 4,7 & 23,0 & 727 & 355 & 1006,91 \\
\hline P-05 (09/09) & Fluv-mar & 1246 & 387,76 & 150 & 5,86 & 725 & 87,1 & 56,5 & 77,3 & 5651 & 2808 & 479,11 \\
\hline P-01A (10/09) & Macacu profundo & 2,1 & 0,77 & 318 & 0,03 & 107,5 & 3,4 & 0,5 & 13,3 & 349 & 175 & 181,15 \\
\hline P-01B (10/09) & Macacu médio & 2,0 & 0,15 & 105 & 0,03 & 34,9 & 4,8 & 0,7 & 8,5 & 177 & 88 & 126,07 \\
\hline P-01C (10/09) & Aluvial-Lac. & 459 & 4,00 & 37 & 6,56 & 107 & 16,7 & 15,0 & 126,3 & 1564 & 782 & 157,66 \\
\hline P-02A (10/09) & Macacu profundo & 4,3 & 7,78 & 204 & 0,05 & 27,4 & 1,3 & 3,0 & 43,1 & 331 & 166 & 196,27 \\
\hline P-02B (10/09) & Macacu profundo & 3,9 & 5,75 & 30,1 & 0,04 & 6,0 & 2,7 & 0,7 & 7,3 & 75 & 37 & 207,90 \\
\hline P-02C (10/09) & Macacu raso & 5,0 & 18,88 & 52 & 0,06 & 10,6 & 1,7 & 1,5 & 13,5 & 176 & 88 & 194,86 \\
\hline
\end{tabular}


Tabela 2 - Dados hidrogeoquímicos dos sistemas aquíferos da Bacia Sedimentar do Macacu (continuação).

Table 2 - Data hydrogeochemical aquifer systems of Sedimentary Basin Macacu (continued).

\begin{tabular}{|c|c|c|c|c|c|c|c|c|c|c|c|c|}
\hline & & $\mathrm{Cl}^{-}$ & $\mathrm{SO}_{4}^{-2}$ & $\mathrm{HCO}_{3}^{-}$ & $\mathrm{Br}^{-}$ & $\mathbf{N a}^{+}$ & $\mathbf{K}^{+}$ & $\mathrm{Mg}^{+2}$ & $\mathrm{Ca}^{+2}$ & \multirow{2}{*}{$\begin{array}{c}\mathbf{C E} \\
(\mathrm{uS} / \mathrm{cm})\end{array}$} & \multirow{2}{*}{$\begin{array}{c}\text { TDS } \\
(\mathrm{mg} / \mathrm{L})\end{array}$} & \multirow{2}{*}{$\begin{array}{c}\mathbf{r C l} / \mathbf{B r} \\
(\mathrm{meq} / \mathrm{L})\end{array}$} \\
\hline ID & Aquifero & \multicolumn{8}{|c|}{$(\mathrm{mg} / \mathrm{L})$} & & & \\
\hline P-03A (10/09) & Macacu profundo & 5,6 & 9,55 & 270 & 0,05 & 107,3 & 1,5 & 0,4 & 5,9 & 336 & 168 & 259,69 \\
\hline P-03B (10/09) & Aluvial-Lac. & 6,9 & 4,24 & 224 & 0,05 & 82,1 & 5,7 & 0,9 & 9,4 & 340 & 170 & 300,16 \\
\hline P-05 (10/09) & Fluv-mar & 919 & 120,1 & 100 & 3,99 & 251,8 & 67,0 & 40,9 & 53,0 & 5526 & 1763 & 519,36 \\
\hline P-01A (11/09) & Macacu profundo & 3,2 & 1,39 & 156 & 0,03 & 56,7 & 2,7 & 0,9 & 13,7 & 352 & 175 & 277,23 \\
\hline P-01B (11/09) & Macacu médio, & 2,7 & 1,67 & 90 & 0,02 & 21,8 & 2,8 & 0,7 & 7,5 & 194 & 98 & 244,53 \\
\hline P-01C (11/09) & Aluvial-Lac, & 444 & 0,56 & 34 & 2,27 & 96,1 & 10,6 & 17,9 & 88,9 & 1637 & 814 & 441,16 \\
\hline P-02A (11/09) & Macacu profundo & 14,2 & 4,71 & 142 & 0,08 & 29,1 & 4,3 & 10,3 & 7,5 & 362 & 181 & 379,40 \\
\hline P-02B (11/09) & Macacu profundo & 10,8 & 3,96 & 20,2 & 0,05 & 4,9 & 1,7 & 0,7 & 7,0 & 90 & 40 & 480,58 \\
\hline P-02C (11/09) & Macacu raso & 4,4 & 7,87 & 64,0 & 0,05 & 15,8 & 4,1 & 0,01 & 7,8 & 150 & 75 & 213,08 \\
\hline P-03A (11/09) & Macacu profundo & 4,0 & 5,25 & 212 & 0,04 & 56,8 & 1,1 & 1,0 & 11,5 & 381 & 172 & 253,07 \\
\hline P-03B (11/09) & Aluvial-Lac, & 9,1 & 5,14 & 184 & 0,06 & 48,6 & 3,7 & 9,9 & 16,8 & 322 & 158 & 349,61 \\
\hline P-05 (11/09) & Fluv-mar & 803 & 100,7 & 761 & 6,61 & 628,5 & 36,3 & 66,7 & 21,3 & 5532 & 2666 & 273,98 \\
\hline P-01A (12/09) & Macacu profundo & 2,8 & 1,35 & 225 & 0,02 & 59,2 & 2,7 & 0,3 & 18,7 & 354 & 176 & 294,76 \\
\hline P-01B (12/09) & Macacu médio & 2,4 & 1,70 & 101 & 0,02 & 24,9 & 2,9 & 0,6 & 8,8 & 185 & 93 & 294,36 \\
\hline P-01C (12/09) & Aluvial-Lac, & 573 & 0,98 & 38 & 3,12 & 124,4 & 11,9 & 22,8 & 116,1 & 2075 & 1032 & 414,12 \\
\hline P-02A (12/09) & Macacu profundo & 18,2 & 18,19 & 208 & 0,11 & 42,9 & 5,3 & 11,4 & 17,8 & 403 & 196 & 358,49 \\
\hline P-02B (12/09) & Macacu profundo & 6,1 & 7,35 & 102 & 0,06 & 6,9 & 1,6 & 18,7 & 5,2 & 76 & 37 & 237,24 \\
\hline $\mathrm{P}-02 \mathrm{C}(12 / 09)$ & Macacu raso & 6,2 & 10,28 & 48 & 0,06 & 17,5 & 4,9 & 0,01 & 4,3 & 152 & 75 & 243,43 \\
\hline P-03A (12/09) & Macacu profundo & 4,9 & 6,88 & 188 & 0,04 & 73,1 & 1,3 & 1,0 & 8,2 & 350 & 175 & 270,80 \\
\hline P-03B (12/09) & Aluvial-Lac, & 8,5 & 5,19 & 166 & 0,05 & 47,7 & 3,8 & 4,4 & 10,8 & 292 & 145 & 365,45 \\
\hline P-05 (12/09) & Fluv-mar & 1139 & 138,7 & 787 & 6,53 & 864,6 & 51,8 & 51,8 & 19,3 & 5348 & 2673 & 392,99 \\
\hline Chuva (12/09) & - & 1,4 & 4,19 & - & 0,04 & 3,9 & 0,1 & - & 0,0 & - & - & 73,86 \\
\hline P-01A $(01 / 10)$ & Macacu profundo & 2,5 & 0,72 & 202 & 0,04 & 53,2 & 2,7 & 0,3 & 14,5 & 352 & 176 & 128,74 \\
\hline P-01B (01/10) & Macacu médio & 1,8 & 0,56 & 87 & 0,03 & 24,0 & 2,9 & 0,4 & 7,9 & 176 & 88 & 122,03 \\
\hline P-01C (01/10) & Aluvial-Lac, & 532 & 0,60 & 29 & 2,03 & 127,9 & 12,7 & 11,5 & 55,0 & 2027 & 1013 & 591,18 \\
\hline P-02A $(01 / 10)$ & Macacu profundo & 7,5 & 1,61 & 159 & 0,07 & 38,9 & 5,0 & 8,0 & 13,1 & 380 & 190 & 261,06 \\
\hline P-02B (01/10) & Macacu profundo & 7,8 & 6,52 & 25,3 & 0,07 & 7,6 & 2,0 & 0,7 & 5,4 & 71 & 35 & 268,50 \\
\hline P-02C (01/10) & Macacu raso & 5,0 & 6,65 & 43 & 0,05 & 13,3 & 4,4 & 0,01 & 3,3 & 118 & 58 & 243,99 \\
\hline $\mathrm{P}-05(01 / 10)$ & Fluv-mar & 1243 & 148,8 & 754 & 4,71 & 932,9 & 54,1 & 31,6 & 9,8 & 5487 & 2742 & 595,17 \\
\hline
\end{tabular}




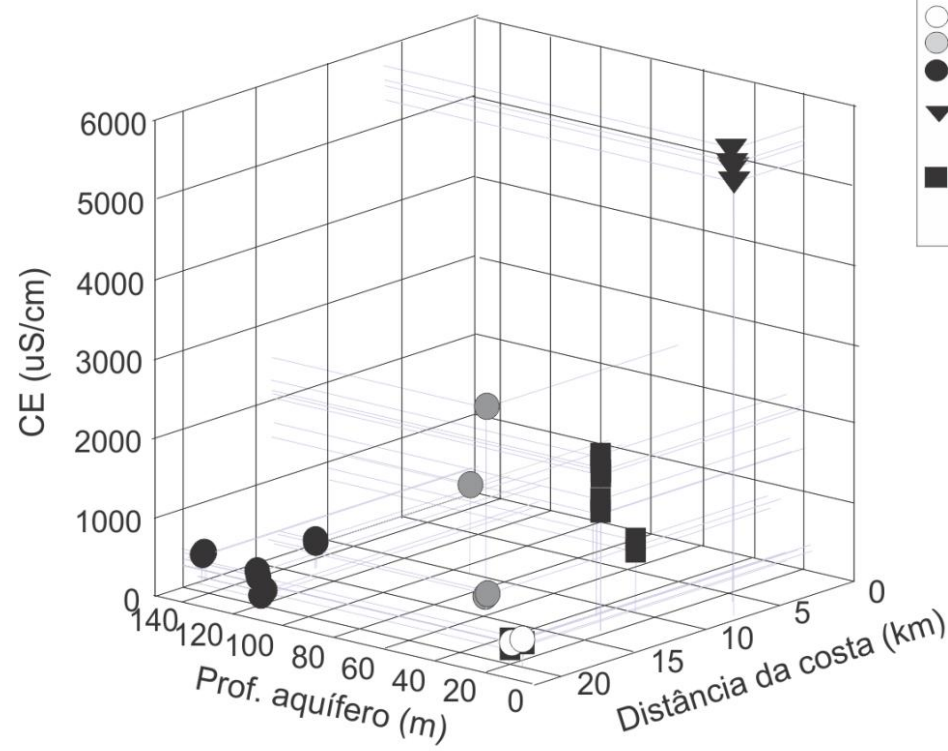

\section{LEGENDA \\ Aquífero Macacu}

captação entre $24-30 \mathrm{~m}$

captação entre $60-95 \mathrm{~m}$

captação a partir $100 \mathrm{~m}$

$\checkmark$ Aquífero Fluvial-Marinho

captação em torno de $15 \mathrm{~m}$

Aquífero Aluvial-Lacustrino

captação entre 15 - 29m

Figura 4 - Distribuição espacial tridimensional da CE nos aquíferos sedimentares da Bacia do Macacu. Figure 4 - Three-dimensional spatial distribution of EC in sedimentary aquifers Basin Macacu.

Ainda em relação à $\mathrm{CE}$, de acordo com a análise de Spearman (Tabela 3), respectivamente o $\mathrm{Na}^{+} \mathrm{e} \mathrm{Ca}^{+2}$ dissolvidos apresentaram as correlações mais significativas com a CE (e TDS), além do $\mathrm{Mg}^{+2}, \mathrm{~K}^{+} \mathrm{e} \mathrm{Cl}^{-}$que também apresentaram correlações significativas $(>0,60)$.

As concentrações dos íons maiores dis- solvidos na água subterrânea foram representadas em diagramas de Piper, conforme Figura 5. No período estudado foi possível distinguir 4 (quatro) tipos de águas subterrâneas: bicarbonatadacálcica, bicarbonatada-sódica, cloretada-cálcica e sódica.

Tabela 3 - Correlação matricial entre íons e parâmetros físico-químicos.

Table 3 - Correlation matrix between ions and physicochemical parameters.

\section{Variáveis}

$\begin{array}{cccccccccccc}\mathbf{C l} & \mathbf{C l} & & & & & & & & \\ \mathbf{S O}_{4} & \mathbf{0 , 6 0} & \mathbf{S O}_{4} & & & & & & & \\ \mathbf{H C O}_{3} & -0,08 & 0,20 & \mathbf{H C O} & & & & & & \\ \mathbf{B r} & \mathbf{0 , 7 6} & 0,46 & -0,17 & \mathbf{B r} & & & & & \\ \mathbf{N a} & 0,46 & 0,19 & 0,45 & 0,30 & \mathbf{N a} & & & & \\ \mathbf{K} & \mathbf{0 , 6 6} & 0,29 & -0,07 & \mathbf{0 , 5 9} & \mathbf{0 , 5 4} & \mathbf{K} & & & & \\ \mathbf{M g} & \mathbf{0 , 7 0} & 0,31 & 0,07 & \mathbf{0 , 7 1} & 0,44 & \mathbf{0 , 5 9} & \mathbf{M g} & & & \\ \mathbf{C a} & 0,40 & 0,09 & 0,10 & 0,42 & \mathbf{0 , 6 0} & \mathbf{0 , 6 5} & \mathbf{0 , 6 2} & \mathbf{C a} & & \\ \mathbf{C E} & \mathbf{0 , 6 2} & 0,26 & 0,39 & 0,46 & \mathbf{0 , 8 0} & \mathbf{0 , 6 3} & \mathbf{0 , 6 4} & \mathbf{0 , 7 0} & \mathbf{C E} & \\ \mathbf{T D S} & \mathbf{0 , 6 4} & 0,28 & 0,40 & 0,49 & \mathbf{0 , 7 9} & \mathbf{0 , 6 3} & \mathbf{0 , 6 5} & \mathbf{0 , 6 9} & \mathbf{0 , 9 9} & \mathbf{T D S}\end{array}$




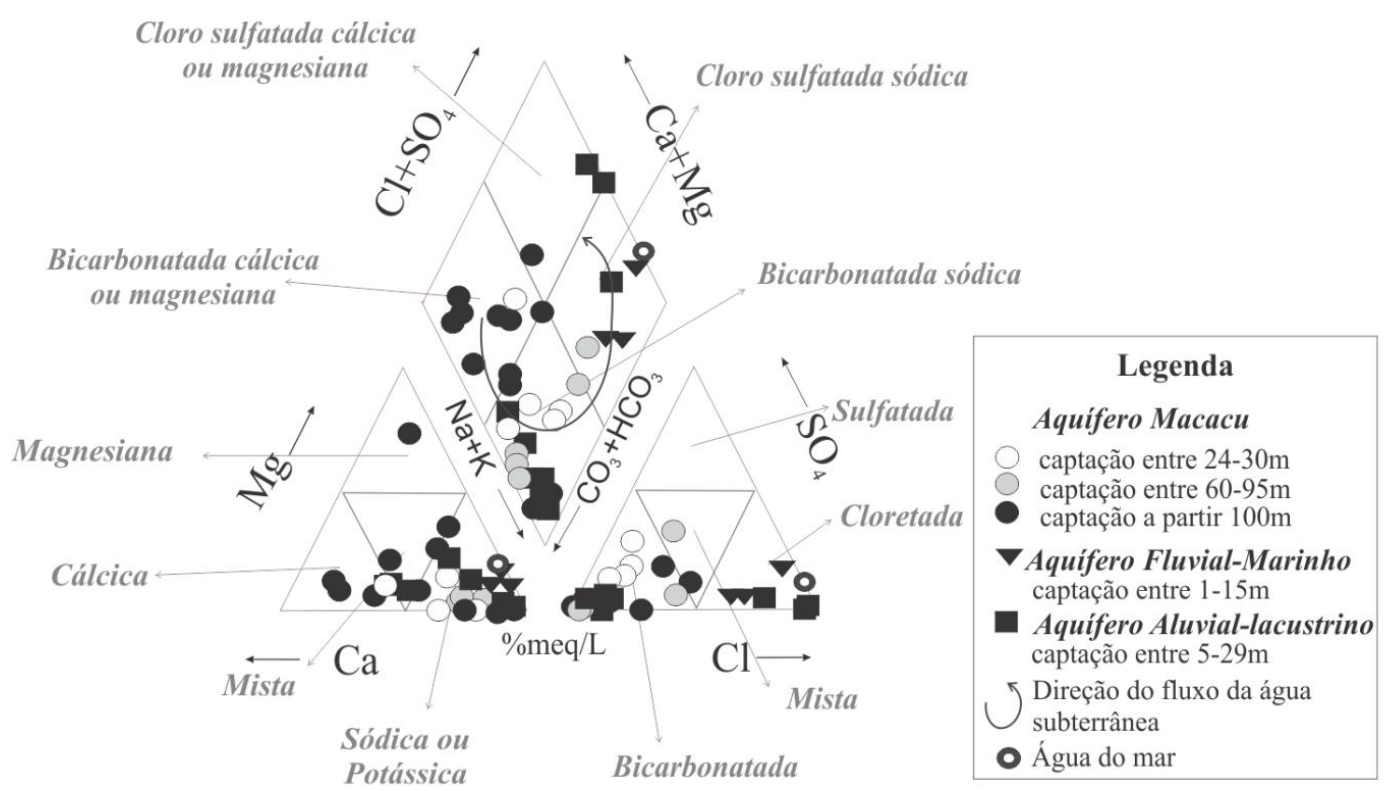

Figura 5 - Diagrama de Piper das águas subterrâneas na área de estudos.

Figure 5 - Piper diagram of groundwater in the study area.

A partir das características hidroquímicas das águas subterrâneas associadas ao tipo de aquífero e à localização dos poços de monitoramento ao longo da Bacia Sedimentar, observa-se que:

- Zonas profundas, próximo à cabeceira da bacia, onde se encontra o Sistema Aquífero Macacu predominam águas bicarbonatadascálcicas (P-02) e bicarbonatadas-sódicas (P03);

- Zonas intermediárias e profundas, na região central da bacia, predominam águas bicarbonatadas-sódicas (P-01A, P-01B) e nas zonas intermediárias rasas ocorrem águas do tipo cloretadas-sódicas (P-01C);

- Zonas rasas, próximas à região costeira, na área de descarga do fluxo subterrâneo predominam águas cloretadas-sódicas (P-04, P-05) sendo para os sistemas aquíferos Aluviallacustrino e Flúvio-marinho notável a influência do $\mathrm{Na}^{+} \mathrm{e} \mathrm{Cl}^{-}$.

Vale ressaltar ainda, que, assim como no estudo de Pinto et al (2006) realizado para águas subterrâneas de Guapimirim, o íon bicarbonato também foi dominante neste estudo. Também foi possível identificar na área estudada um enriquecimento gradativo de $\mathrm{Na}^{+}$e das águas cloretadas sódicas que Pinto op cit caracteriza como possíveis existências de depósitos subterrâneos formados pela evaporação de mares antigos.

A elevação do conteúdo de $\mathrm{Na}^{+}$e a diminuição do $\mathrm{Ca}^{2+} \mathrm{em}$ função da percolação da água pela bacia aponta a ocorrência do fenômeno de troca iônica na matriz dos aquíferos. Após a constatação do aumento da concentração de $\mathrm{Cl}^{-} \mathrm{em}$ zonas mais rasas próximas à costa, foram cogitadas hipóteses como i) contaminação por intrusão salina; ii) impacto nos aquíferos a partir de águas superficiais contaminadas por esgoto e iii) lixiviação de sais existentes naturalmente nos sedimentos das formações aquíferas. Tais hipóteses serão discutidas e delineadas ao longo deste estudo.

Quanto à influência da intrusão marinha, segundo IGME (2009), em aquífero costeiro, em condições naturais, ocorre o contato da água doce com a água do mar e, considerando que essas águas são miscíveis, existe uma zona de transição onde estas águas se mesclam, progressivamente, através de processos de difusão. $\mathrm{O}$ deslocamento dessa zona de mescla ocorre por redução do fluxo de água doce para o mar; variação da permeabilidade dos sistemas aquíferos em função da heterogeneidade litológica, além da diferença de densidade e oscilações das marés.

Por se tratar de um ambiente de transição, com cota altimétrica similar ao nível do mar e ambiente de manguezal, já se esperava significativa influência marinha sobre a água subterrânea no ponto $\mathrm{P}-05$, sujeita, inclusive, à variação da maré. O P-05, portanto, é o ponto monitorado mais próximo da costa (a cerca de $6 \mathrm{~km}$ ), inserido dentro de um ambiente de manguezal (APA Guapimirim), fato que sugere uma relação estreita entre a variação do nível d'água, a condutividade elétrica e a oscilação da maré. 
Com o intuito de comprovar essa relação, a Figura 6 mostra gráficos temporais para o P-05 e P-01C (situados mais próximos da costa) considerando o nível d'água, condutividade elétrica e oscilação da maré monitorada pela Marinha do Brasil, na região da Ilha Fiscal. É possível observar que as máximas e mínimas da variação do nível d'água e da condutividade elétrica do P-05, distintamente do P-01C, estão correlacionadas e podem ser associadas à variação da maré. Esta constatação confirma que a área do P-05 encontra-se na zona de mescla entre a água salgada e a água subterrânea, fato que não ocorre no P-01C, instalado fora da área de mangue, distante cerca de $14 \mathrm{~km}$ da costa.
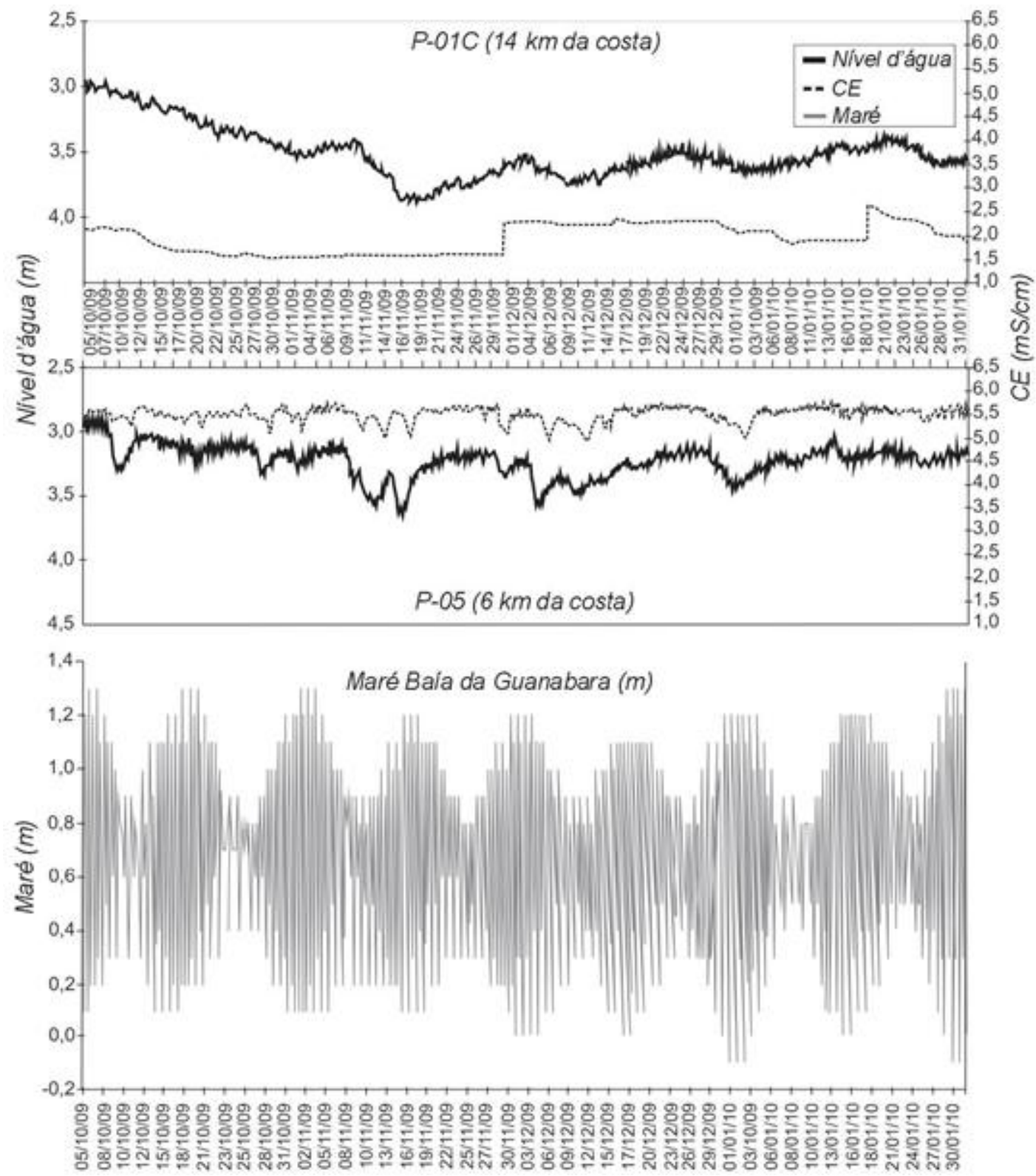

Figura 6 - Nível d'água X CE (P-01C e P-05) comparado com a variação de maré da Baía da Guanabara (Tábua de maré da Ilha Fiscal-RJ).

Figure 6 - Water Level X EC (P-01C and P-05) compared to the tidal variation of Guanabara Bay.

Considerando que a influência da água do mar afeta apenas o Sistema Aquífero FluvialMarinho e que o aumento dos valores de CE e dos íons como $\mathrm{Cl}^{-}$e $\mathrm{Na}^{+}$foi verificado em outros sistemas aquíferos, foi utilizada a razão entre os íons $\mathrm{Cl}^{-}$e o $\mathrm{Br}^{-}$para se estabelecer os índices hidrogeoquímicos que possam subsidiar a compreensão da origem da salinidade dos sistemas sedimentares da Bacia do Macacu.

As razões $\mathrm{rCl} / \mathrm{rBr}$ calculadas para este estudo estão apresentadas na Tabela 2. A água da chuva coletada e analisada em dezembro/2009 apresentou uma $\mathrm{rCl} / \mathrm{rBr}$ de 74 , estando dentro das expectativas, já que, segundo Davis et al. (1998), 
a precipitação atmosférica geralmente tem razões entre 50 - 150. Os valores da razão $\mathrm{rCl} / \mathrm{rBr}$ ao serem associados com as concentrações de $\mathrm{Cl}^{-}$ verificadas nos aquíferos e apresentadas em gráfico com escala logarítmica (Figura 7), evidenciou quatro (4) grupos de procedências para origem da salinização das águas da área em questão.

- O Grupo G1 é formado por águas de recarga que apresentaram valores da $\mathrm{rCl} / \mathrm{rBr}$ entre 100 - 539 e concentrações de $\mathrm{Cl}^{-}$que não ultrapassam $25 \mathrm{mg} / \mathrm{l}$ pertencentes ao Aquífero Macacu influenciadas diretamente pela precipitação.

- O Grupo G2, localizado numa área de descarga, é formado por águas subterrâneas que apresentam valores de $\mathrm{rCl} / \mathrm{rBr}$ entre 1.007 1.500 e concentrações de $\mathrm{Cl}$ que variam de 141 até $178 \mathrm{mg} / \mathrm{l}$. Estas são águas dos sistemas aquíferos Aluvial-lacustrino e Macacu coletadas no poço multinível P-04. O aumento da $\mathrm{rCl} / \mathrm{rBr}$ nesse grupo se dá principalmente pela localização do P-04, o qual encontra-se em Itambi, onde o fluxo de água subterrânea passa pelo Membro Rio Vargem da Formação Macacu, onde se espera a existência de sais de Halita precipitados em seus sedimentos.

- O Grupo G3 é formado por águas subterrâneas que apresentam razões $\mathrm{rCl} / \mathrm{rBr}$ entre $10-$ 591, mas com concentrações de $\mathrm{Cl}^{-}$que varia- ram de 443 até $745 \mathrm{mg} / \mathrm{l}$. Neste grupo encontram-se águas subterrâneas do sistema aquífero Aluvial-lacustrino do Quaternário, na região de Porto das Caixas (P-01C). As águas subterrâneas deste grupo (G3) possuem altas concentrações de $\mathrm{Cl}^{-}$, porém, também possuem significativos valores de $\mathrm{Br}^{-}$que reduzem a $\mathrm{rCl} / \mathrm{rBr}$. Nesse ponto, as altas concentrações de $\mathrm{Cl}^{-}$podem estar associadas ao lançamento "in natura" de esgotos domésticos no Rio Caceribu. Este rio pode contribuir com aporte de água para o aquífero, já que ele se encontra a uma distância de 350m. Davis et. al. (1998), mostra que águas subterrâneas rasas podem apresentar baixas $\mathrm{rCl} / \mathrm{rBr}$ em aquíferos, onde há sensível contribuição do $\mathrm{Br}^{-}$em função de altas concentrações de matéria orgânica.

- O Grupo G4 é formado por águas subterrâneas que apresentam razões $\mathrm{rCl} / \mathrm{rBr}$ entre 274 - 595 e com as maiores concentrações de $\mathrm{Cl}^{-}$, entre 803 até $1246 \mathrm{mg} / \mathrm{l}$. Nesse grupo encontram-se águas subterrâneas do sistema Aquífero Fluvial-marinho da região de manguezal da APA Guapimirim. Essa região formada por sedimentos argilosos ricos em matéria orgânica que também possuem substanciais concentrações de $\mathrm{Br}^{-}$, mas a intrusão marinha direta geralmente mantém altas as razões $\mathrm{rCl} / \mathrm{rBr}$.

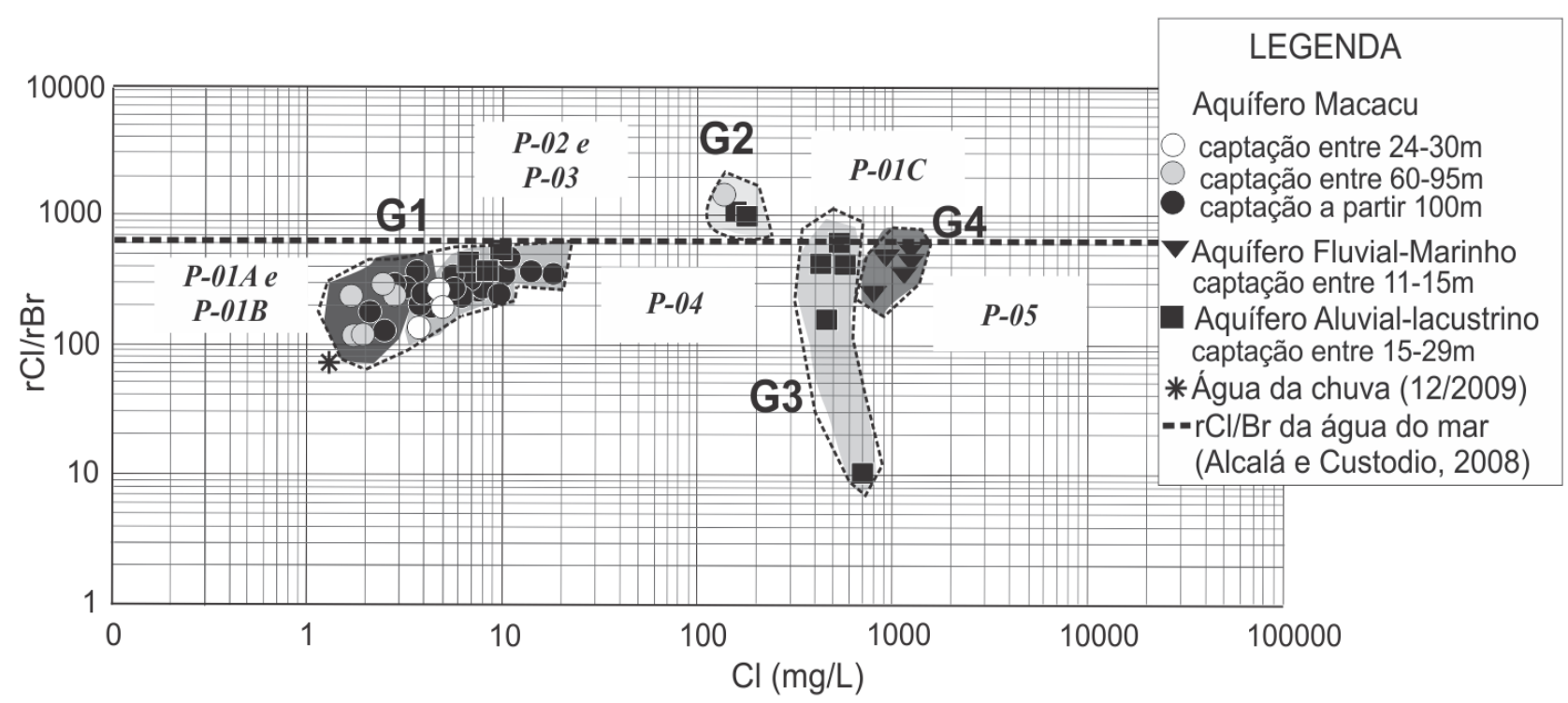

Figura 7 - rCl/rBr associada a concentração de cloreto nos aquíferos sedimentares de Itaboraí.

Figure $7-\mathrm{rCl} / \mathrm{rBr}$ associated with chloride concentration in sedimentary aquifers in Itaboraí.

Apesar de distribuídos numa área restrita $\left(375 \mathrm{~km}^{2}\right)$, os aquíferos da Bacia Sedimentar do Macacu possuem larga faixa de salinidades que reflete em diversificados comportamentos geoquímicos conforme discutido ao longo deste estudo. 


\section{CONCLUSÕES}

A evolução hidroquímica da água subterrânea nos sistemas aquíferos sedimentares da região de Itaboraí é caracterizada por uma mudança gradual de águas de fácies bicarbonatada-cálcica nas áreas de recarga, limítrofes a bacia sedimentar do Macacu, para águas do tipo bicarbonatada-sódica na região central da bacia e posteriormente para cloretada-sódica em áreas de descargas, próximas ao litoral. É evidente, portanto, um decréscimo em $\mathrm{Ca}^{2+}$ acompanhado por um aumento de $\mathrm{Na}^{+}$que estaria associado a trocas iônicas entre a água infiltrada e a matriz argilosa dos aquíferos.

A partir da razão $\mathrm{rCl} / \mathrm{rBr}$, as águas subterrâneas das formações sedimentares da Bacia do Macacu podem ser separadas em quatro (4) gru pos distintos quanto à salinidade: i) águas subter- râneas de recarga rápida, $\mathrm{com} \mathrm{rCl} / \mathrm{rBr}$ próximas aos valores encontrados na água da chuva, representada principalmente pelo Sistema Aquífero Macacu; ii) águas subterrâneas localizadas em áreas de descarga, afetadas pela dissolução da Halita precipitada em sedimentos paludiais, como ocorrem na região de Itambi (P-04A e P-04B); iii) águas subterrâneas que, apesar de altas concentrações de cloreto, possuem relevantes valores de brometo associados à presença da matéria orgânica (P-01C), como ocorre no sistema Aluviallacustrino e; iv) águas subterrâneas que possuem altas concentrações de cloreto e altas razões $\mathrm{rCl} / \mathrm{rBr}$ associadas à intrusão de cunha salina $(\mathrm{P}$ 05), que ocorrem no sistema Fluvial-marinho.

\section{AGRADECIMENTOS}

Ao INCT-TMOcean (CNPq) e FAPERJ (Fundação de Amparo a Pesquisa do Estado do Rio de Janeiro) pelo apoio financeiro.

\section{REFERÊNCIAS}

ALCALÁ, F. J.; CUSTODIO E. La relacion Cl/Br como indicador del origen de la salinidad en algunos acuíferos de España y Portugal. Groundwater Flow Understanding, from Local to Regional Scale. In: CONGRESO INTERNATIONAL ASSOCIATION HYDROGEOLOGISTS - ALHSUD, 33., 2008. Proceedings... Zacatecas, 2008. 4 p

ALMEIDA, F. F. M. O Craton do São Francisco. Rev. Bras. Geociências, v. 7, p. 349- 364, 1977.

ALMEIDA, F. F. M. O Craton do Paramirim e suas relações com o do São Francisco. In: SBG, SIMPÓSIO DO CRATON DO SÃO FRANCISCO E SUAS FAIXAS MARGINAIS, 1., 1981, Salvador. Anais... Salvador, 1981. p. 1-10.

BOGGS, J. M.; ADAMS, E. E. Field study of dispersion in a heterogeneous aquifer 4: Investigation of adsorption and sampling bias. Water Resources Research, v. 28, n. 12, p. 3325-3338, 1992.

BOWMAN, R. S. Evaluation of some new tracers for soil water studies. Soil Science Soc. Amer. Jour., v. 48, n. 5, p. 987-993, 1984

BOWMAN, R. S.; RICE, R. C. Chemical tracers - Their use in measuring deep percolation rates. In: THIRD DEEP PERCOLATION SYMPOSIUM, 7., 1985, Scottsdale, Arizona, November 1984. Proceedings... Phoenix, Arizona: Arizona Dept. Water Resources, 1985.

CARTWRIGHT, I.; WEAVER, T. R.; FIFIELD, L. K. Cl/Br ratios and environmental isotopes as indicator of recharge variability and groundwater flow: An example from the southeast Murray Basin, Australia. Chemical Geology, n. 231, p. 38-56 p, 2006.
COELHO, C. E. S. Contribuição ao estudo da gênese das mineralizações de fluorita do Distrito de Tanguá, Município de Itaboraí - RJ. 1987. 194 f. Tese (Mestrado) - Departamento de Geociências, Universidade de Brasília, Brasília, 1987.

CPRM - COMPANHIA DE PESQUISA DE RECURSOS MINERAIS - SERVIÇO GEOLÓGICO DO BRASIL. Programas Levantamentos Geológicos Básicos do Brasil: Geologia do Estado do Rio de Janeiro: Texto explicativo do Mapa Geológico do Estado do Rio de Janeiro. Brasília/DF: MME, 2001. 1 CD-ROM.

CUSTODIO E.; LLAMAS. M. R. Hidrologia subterranea. Barcelona: Editora Omega, 1983. 2350 p.

DAVIS, S. N.; CAMPBELL, D. J.; BENTLEY, H. W.; FLYNN, T. J. Ground water tracers. Dublim, Ohio: National Water Well Association, 1985.

DAVIS, S. N.; WHITTEMORE, D. O.; MARTIN, J. F. Uses of Chloride/Bromide Ratios in Studies of Potable Water. Ground-Water, v. 36, n. 02, p. 338-350, 1998.

DAVIS, S. N.; CECIL, L. D.; ZREDA, M.; MOYSEY, S. Chlorine-36, bromide, and the origin of spring water. Chemical Geology, v. 179, p. 3-16, 2001.

D'ALCOLMO, M. T.; FERRARI, A. L.; MELLO, E. F.; VAZ, M. A. A.; BRENNER, T. L.; SILVA, V. P.; NASSAR, W. M. Bloco Baía de Guanabara, Folhas: Itaboraí, Baía de Guanabara, Maricá e Saquarema. Relatório Final. Niterói: GEOMITEC - DRM/RJ, 1982. 
DREVER, J. I. The Geochemistry of Natural Waters: Surface and Groundwater Environments, New Jersey, USA: Prentice-Hall, 1997. 436 p.

DRM - DEPARTAMENTO DE RECURSOS MINERAIS / GEOMITEC. Projeto Carta Geológica do Estado do Rio de Janeiro - Bloco Baia de Guanabara, RJ. Escala 1:50.000. Rio de Janeiro, 1981.

FERRARI, A. L. Evolução Tectônica do Graben da Guanabara. Rift da Guanabara. 2001. 421 f. Tese (Doutorado) Instituto de Geociências - USP, São Paulo, 2001.

ECOLOGUS-AGRAR. Plano Diretor de Recursos Hídricos da Baía de Guanabara (PDRHBG). Relatório Final. Rio de Janeiro: Consórcio, 2005. 190 p.

FERRARI, A. L.; FERRAZ. Uma Nova Interpretação para a Depressão Gravimétrica de Itaboraí/RJ. In: CONGRESSO BRASILEIRO DE GEOLOGIA, 35., 1988, Belém. Anais... Belém, 1988.

HASUI, Y.; CARNEIRO, C. D. R.; COIMBRA, A. M. The Ribeira folded belt. Rev. Bras. Geociências, n. 5, p. 257-266, 1975.

LEAP, D. I. Testing bromide as a surrogate for tritium in tracing ground-water movement through a dolomitic aquifer. Geol. Soc. America, n. 7, p. 543, 1982.

MEIS, M. R. M. \& AMADOR, E. S. Contribuição ao estudo do Neocenozóico da baixada da Guanabara; Formação Macacu. Rev. Bras. Geociências, São Paulo, n. 7, 2, p. 150-174, 1977.

PENHA, H. M.; FERRARI, A. L.; RIBEIRO, A.; AMADOR, E. S.; PENTAGNA, F. P.; JUNHO, M. C. B.; BRENNER, T. L. Projeto Carta Geológica do Estado do Rio de Janeiro, Folha Petrópolis (Relatório Final). Rio de Janeiro: DRM/ UFRJ, 1979. 194 p.

SANT"ANNA, L. G.; RICCOMINI, C. Cimentação Hidrotermal em Depósitos Sedimentares Paleogênicos do Rift Continental do Sudeste do Brasil: Mineralogia e Relações Tectônicas. Rev. Bras. Geociências, n. 31, v.2, p.231-240, 2001.
SCHLUMBERGER WATER SERVICES. Estudo Regional de Caracterização Hidrogeológica e Determinação de Fluxos de Água Subterrânea em Itaboraí (Relatórios 2 e 3 Modelo Hidrogeológico). Rio de Janeiro, 2007. 88 p.

SCHLUMBERGER WATER SERVICES. Estudo Regional de Caracterização Hidrogeológica e Determinação de Fluxos de Água Subterrânea em Itaboraí. Relatório de Instalação dos Poços de Monitoramento Multi-nível. Rio de Janeiro, 2008. $47 \mathrm{p}$.

SCHOELLER, H. Geochemie des eaux souterraines. Revue de L'Institute Français du Petrole.10Les eaux souterraines, 1955. p. $230-244$.

SEMADS - SECRETARIA DE ESTADO DE MEIO AMBIENTE E DESENVOLVIMENTO SUSTENTÁVEL. Subsídios para Gestão dos Recursos Hídricos das Bacias Hidrográficas dos Rios Macacu, Macaé e Macabu. Rio de Janeiro: Projeto PLANÁGUA/SEMADS/GTZ, 1999. 280 p.

SERLA - FUNDAÇÃO SUPERINTENDÊNCIA ESTADUAL DE RIOS E LAGOAS. Relatório de Distribuição mensal histórica de precipitação na Estação de Monitoramento de Quizanga, situada a norte da área de estudo, no Rio Guapiaçu entre 1997 e 2005. 2007.

SIMERJ - SECRETARIA DE CIÊNCIA E TECNOLOGIA DO ESTADO DO RIO DE JANEIRO. Dados do Sistema de Meteorologia do Estado do Rio de Janeiro. Disponível em: $<$ http://www.simerj.com/default_reg_cbmerj.php>. Acesso em: jan. 2011.

SONOKI, I. K.; GARDA, G. M. Idades K-Ar de rochas alcalinas do Brasil Meridional e Paraguai Oriental: compilação e adaptação às novas constantes de decaimento. Bol. IGUSP, Série Científica, n. 19, p. 63 - 85, 1988.

TENNYSON, L. C.; STTERGREN, C. D. Percolate water and bromide movement in the zone of effluent irrigation sites. Water Resources Bulletin Amer. Water Resources Assoc., v. 16, n. 3, p. 433 - 437, p. 1980. 